\title{
SKIN DISEASES;
} PREVALENCE IN PEDIATRIC PATIENTS IN HYDERABAD: SINDH, PAKISTAN.

1. FCPS (Pediatrics)

Assistant Professor, Department of Pediatric Muhammad Medical College, Mir Pur Khas, Sindh.

2. $\mathrm{MRCPCH}$

Professor and Chair Person, Department of Pediatrics, Liaquat University of Medical and Health Sciences, Hospital, Hyderabad.

3. MCPS (Family Medicine), M. Phil (Pharmacology) Consultant Family Physician and Assistant Professor, Department of Pharmacology, Isra University Hyderabad.

Correspondence Address: Dr. Ashique Ali Arain

Consultant Family Physician and Assistant Professor, Department of Pharmacology, Isra University Hyderabad. ashiquepcmd77@yahoo.com

Article received on: 23/02/2017

Accepted for publication: 15/05/2017

Received after proof reading: 03/07/2017

INTRODUCTION

Skin diseases in children have not been studied well in Pakistan while many countries of the world has emphasized well on this issue. These include atopic dermatitis, Pityriasis capita, Scabies, mycosis, Seborrheic dermatitis. Atopic dermatitis affects $60 \%$ of infants from $4-12$ months usually $50 \%$ of them recover by 18 months and $25 \%$ present below the age of 5years while children from2-12years are also affected. Common presentation is with rash on the face, neck and extensor aspects of the extremities. Pityriasis capita is a focal or diffuse form of seborrheic dermatitis characterized by scaly and crusting lesion on scalp but may involve the whole body including face, axillae and diaper area. Candidial infection also results in dermatitis in diaper area with papular and vesiculopustular appearance along with sharply demarcated edges and satellite leisons adjacent to primary

\begin{abstract}
Imran Ahmed Ghirano', Salma Sheikh², Ashique Ali Arain ${ }^{3}$
ARTRCT... Background: Skin gives beauty and protection to the body of all living anima problems that need to be addressed and managed early to avoid further complications. Material and Methods: 518 Children of both sexes with age range from 1 months to 11 years (finering from any kind of skin disease were randomly selected after taking consent from parents. Study Design: It was an observational study. Study Settings: This study was Study Duration: Study duration was 6months from March 2012 August 2012. Sampling Technique: Probability Sampling (Simple Random Sampling) was used to select the study and percentage of the data. Mean and standard of numerical variables were calculated was the study population was male children and $43 \%$ were female showing high prevalence of skin diseases in male as compared to females. Scabies was found to be most common in both groups (32.43\%) followed by Folliculitis (13.13\%), Impetigo (11.39\%) and Tenia Capitus (8.69\%) mean age of our study patient was 5 years. Conclusion: Skin diseases are more prevalent in
\end{abstract} Key words: $\quad$ Atopic Dermatitis, Pityriasis Capita, Acne, Candediasis.
Article Citation: Ghirano IA, Sheikh S, Arain AA. Skin diseases; prevalence in pediatric patients in Hyderabad: Sindh, Pakistan. Professional Med J 2017;24(7):1031-1035. DOI: 10.17957/TPMJ/17.3899

focus. ${ }^{1}$ Dermatological diseases are frequent and common in children. Diseases like acne and alopeciaareata although notvery serious problems but disturbing and distressing for children. Some chronic dermatological diseases e.g psoriasis, atopic dermatitis, and vitiligo have significant psychological impact due to disease progression and complications in addition to therapeutic measures safety are of great concern. ${ }^{2}$ Some dermatological diseases are frequently associated with the variations of seasons. Acne vulgaris, contact dermatitis, atopic dermatitis, psoriasis, alopecia areata and xerosis are mostly observed in winter season. On the other hand insect bites, eczema, vitiligo, impetigo and tinea corporis show more association with summer. ${ }^{3}$ The exact epidemiologic figures prevalence or incidence of skin diseases in the general population are still lacking however different hospital-based studies show the skin diseases need more attention. 
$21 \%$ of the patients consulting the GPs in UK present with dermatological problems. 235/1000 children with age range $0-17$ years visited the health care providers in 2001 in Netherlands and most of them were bacterial, fungal, viral, eczematous and traumatic skin diseases. 6300 pediatric patients were reported in Turkey to visit the dermatological clinics with age range 0-16 years. ${ }^{4} \mathrm{WHO}$ reported a mortality rate of 20000 in year 2001due to dermatological diseases in SubSaharan Africa that was comparable to mortality rates associated with other diseases in the region including hepatitis, meningitis and rheumatic heart diseases. ${ }^{5}$ The WHO (World Health Organization) is continuously focusing and stressing to overcome the burden of the neglected tropical diseases (NTDs). Elimination of onchocerciasis is one of those goals of WHO to free the African countries by 2020 from this condition. ${ }^{6}$ Skin diseases involve all age population but more common in youngers, morbidities associated with them further makes them more important public health problem associated with infections and water inadequacy and overcrowding. ${ }^{7}$ Studies of the pediatric population, which constitutes the cornerstone of the community, can play an important role in determining the policies of protective medicine and public health. New studies will help us to better understand the frequency of dermatological diseases in the pediatric population according to age, gender and season, and take precautions with regard to these conditions. ${ }^{3}$ Current study was aimed to find out the prevalence of various types of skin diseases in children twenty common diseases namely Scabies, Folliculitis, Impetigo, Tenia Capitis, Contact Dermatitis, Atopic Dermatitis, Seborrheic Dermatitis, Intertrigo, Miliara Rubra, Tenia Pedia, Urticaria, Tenia Face, Frunculosis, Candidiasis, Molluscum, Acne, Vetiligo, Herpes Zooster, Hypopigmentation and Warts were selected for the current study.

\section{METHODOLOGY}

The current study was conducted in the Liaquat University of Medical and Health Science hospital OPD. Informed and written consent was obtained on profarma from the parents of the study children. Children suffering from dermatological problem in the age range of 1month-11 years were included in our study while children below 1month and above 11 years were excluded from the study. Children with mal absorption and skin manifestations of other systemic diseases were not included as well. Dermatological diagnosis was made by the consultant dermatologist involved.

\section{Children selection}

Children were examined thoroughly through general physical examination after taking a through history regarding bio data (name age sex), the presenting complain, past history any significant sickness family history.

\section{Ethical Approval}

Prior approval was obtained from LUMHS Hospital ethical review committee to conduct this observational research study.

\section{Statistical Analysis}

Data was analyzed on SPSS version 22 to determine the frequency of various skin diseases in children of both genders. Mean and standard deviation was measured for age in both groups.

\section{RESULTS}

Total 518 pediatric were observed in the current study 296 (57\%) were male and 222(43\%) were females. Mean age in male subjects was found to be $6.9 \pm 1.5$ years while it was $5.5 \pm 1.3$ years in females. Majority of the patients were above 5years 290(55.98\%) while 211(40.73\%) were above the age of 1year and only $17(3.29 \%)$ were below 1year. Scabies was the most prevalent disease in our study accounting (168)32.43\% subjects, Folliculitis was $2^{\text {nd }}$ with $68(13.13 \%)$ patients and Impetigo was $3^{\text {rd }}$ having $59(11.39 \%)$ children. Tenia Capitus was declared $4^{\text {th }}$ with $45(8.69 \%)$ prevalence while none of the other diseases was found above $5 \%$ and were as Intertrigo 4.25\%, Contact Dermatitis $3.86 \%$, Atopic Dermatitis 3.67\%, Miliara Rubra 3.09\%, Seborrheic Dermatitis 2.90\%, Frunculosis 2.72\%, Urticaria $2.51 \%$. 


\begin{tabular}{|l|c|c|}
\hline $\begin{array}{c}\text { Age Range } \\
\text { Categories }\end{array}$ & Frequency & Percentage \\
\hline 0-1 Year & 17 & $3.29 \%$ \\
\hline 2-5 Years & 211 & $40.73 \%$ \\
\hline $6-11$ Years & 290 & $55.98 \%$ \\
\hline
\end{tabular}

\section{Gender distribution}

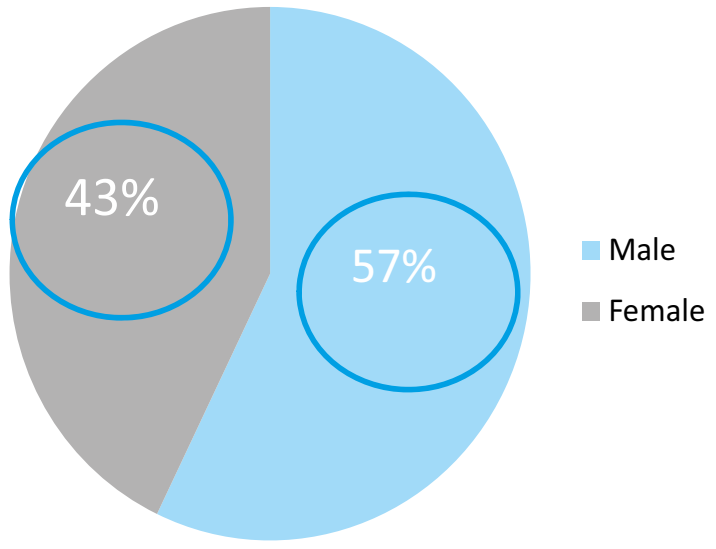

Graphical presentation of Demographic Parameters of study subjects

\begin{tabular}{|c|c|c|c|c|}
\hline $\begin{array}{l}\text { Sr. } \\
\text { No. }\end{array}$ & Diseases & Male & Female & Percentage \\
\hline 1 & Scabies & 99 & 69 & $32.43 \%$ \\
\hline 2 & Folliculitis & 33 & 35 & $13.13 \%$ \\
\hline 3 & Impetigo & 31 & 28 & $11.39 \%$ \\
\hline 4 & Tenia Capitus & 27 & 18 & $8.69 \%$ \\
\hline 5 & Contact Dermatitis & 13 & 07 & $3.86 \%$ \\
\hline 6 & Atopic Dermatitis & 13 & 06 & $3.67 \%$ \\
\hline 7 & $\begin{array}{l}\text { Seborrheic } \\
\text { Dermatitis }\end{array}$ & 12 & 03 & $2.90 \%$ \\
\hline 8 & Intertrigo & 12 & 10 & $4.25 \%$ \\
\hline 9 & Miliara Rubra & 11 & 05 & $3.09 \%$ \\
\hline 10 & Tenia Pedia & 07 & 02 & $1.74 \%$ \\
\hline 11 & Urticaria & 07 & 06 & $2.51 \%$ \\
\hline 12 & Tenia Face & 06 & 02 & $1.54 \%$ \\
\hline 13 & Frunculosis & 05 & 09 & $2.72 \%$ \\
\hline 14 & Candidiasis & 05 & 03 & $1.54 \%$ \\
\hline 15 & Molluscum & 04 & 01 & $0.96 \%$ \\
\hline 16 & Acne & 02 & 07 & $1.74 \%$ \\
\hline 17 & Vetiligo & 03 & 05 & $1.54 \%$ \\
\hline 18 & Herpes Zooster & 02 & 03 & $0.96 \%$ \\
\hline 19 & Hypopigmentation & 02 & 01 & $0.58 \%$ \\
\hline 20 & Warts & 02 & 02 & $0.77 \%$ \\
\hline
\end{tabular}

Skin diseases are among the most common problems encountered in the society and children are also significantly affected by this disorder. The cause seems to be the increased environmental pollution, poor hygiene, over use of chemicals and increased use of pampers in children. Results of our study are in accordance with the previously published study by Ezz. D et al 2012 who also reported high prevalence of dermatological diseases in female children however his study was on school children with age range of 4-12 years and Pediculosis, Tenia Capitis, Pityriasis alba and Urticaria were found to most prevalent diseases. This contrast maybe due to geographical factors influencing the population as it was a Egypt based study ${ }^{2}$. A Turkey based study by Tamer et al 2008 shows Acne vulgaris stood the most prevalent $(12.4 \%)$, atopic dermatitis (11.8\%), contact dermatitis (11.3\%), warts $(9.5 \%)$, seborrheic dermatitis (4.3\%) and impetigo (4.1\%) which is in contrast to our findings. The reason may be poor hygienic conditions in our part of land and European living style of the Turkish public. The age group was also different from our study they included all below 16 years. ${ }^{3} \mathrm{~A}$ large study conducted by Masutaka F et al 2011 in France over 67448 cases of dermatological diseases in 69 University hospitals concluded Atopic dermatitis, molluscum, impetigo, acne and warts the most prevalent skin problems in children. That was also not in agreement with our results. ${ }^{4}$ Fawzia F. Mostafa et al 2011 reported a different prevalence rate for skin diseases in his Egyptian study. The highest prevalence rate was of impetigo (22\%), pediculosis capitis (17.5\%), 
fungal infections (16.3\%), eczema/dermatitis (12.7\%), viral infections (11.2\%), urticaria (6.1\%) again partially consistent to our findings. ${ }^{8}$ Study by Uzma DMR et al 2015 on 100 patients showed prevalence of scabies $2 \%$, Folliculitis $8 \%$, Impetigo $11 \%$, Tenia infection $3 \%$ and declared atopic dermatitis $52 \%$ the most prevalent skin condition. ${ }^{9}$ Navaid et al 2015 reported scabies to be $18 \%$, atopic dermatitis $2 \%$ and seborhoiec dermatitis $2 \%$ in their large size study on 2067 skin patient including the adults that might be a reason of contrast of results. ${ }^{10}$ This may be due to the fact their set up was a private hospital and patients might be from a good socioeconomic background while the current study was in a government hospital where most of the patient were from the poor socioeconomic level. Our study was of a small size in comparison to other studies and limited to one hospital that remained a weakness of current study.

\section{CONCLUSION}

Skin diseases are very common in children specially Scabies, Folliculitis, Impetigo, Tenia Capitis, Contact Dermatitis, Atopic Dermatitis, Seborrheic Dermatitis, Intertrigo, Miliara Rubra, Tenia Pedia, Urticaria, Tenia Face, Frunculosis and Candiasis .Skin diseases are more prevalent in male children in comparison to female.

\section{RECOMMENDATIONS}

Multicenter Large scale studies are recommended all over Pakistan to find out the exact prevalence of the dermatological diseases in children as well as the adults.

It is recommended to improve the awareness status of our public regarding the cleanliness and various kinds of hygienic measures to help in preventing the skin diseases.

\section{DECLARATION BY AUTHORS}

It is here by declared that there lies no conflict of interest among the authors of this current study and no grant or funding was obtained from any agency.

Copyright(c) 15 May, 2017.

\section{REFERENCES}

1. Dermatological disorders in children. Swanson text book of family medicine 2012; 561-566.

2. Ezz El-Dawela, Rehama, Fatehy, Ahmed N.b, Elmoneim et al. Prevalence of skin diseases among school children: a survey in the Sohag Governorate. Journal of the Egyptian Women's Dermatologic Society: January 2012; 9 (1): 47-51.

3. Tamer E, Ilhan MN, Polat M, Lenk N, Alli N. Prevalence of skin diseases among pediatric patients in Turkey. J Dermatol. 2008; 35(7):413-418.

4. Masutaka Furue, Souji Yamazaki, Koichi Jimbow et al. Prevalence of dermatological disorders in Japan: A nationwide, cross-sectional, seasonal, multicenter, hospital-based study. Journal of Dermatology 2011; 38(4)310-320.

5. Roderick Hay, Sandra E. Bendeck, Suephy Chen et al. Skin Diseases. In Disease Control Priorities in Developing Countries. Jamison DT, Breman JG, Measham AR, et al., editors. Washington (DC): New York: Oxford University Press; $2^{\text {nd }}$ edit.2006. 707-721.

6. Hugo C. Turner et al. Reaching the London Declaration on NeglectedTropical Diseases Goals for Onchocerciasis: AnEconomic Evaluation of Increasing the Frequency of Ivermectin Treatment in Africa. Clinical Infectious Diseases 2014; 59(7):923932.

7. Memon KN, Soomro RA, Ansari MS. Pattern of skin diseases in patients visiting a tertiary care health facility at Hyderabad, Pakistan. J Ayub Med Coll Abbottabad. 2011 Oct-Dec; 23(4):37-39.

8. Fawzia F. Mostafa, Aida Abdel H. Hassan et al. Prevalence of skin diseases among infants and children in Al Sharqia Governorate, Egypt. Egyptian Dermatology Online Journal 2011; 8(1): 4-10.

9. Rajar UMD, Kazi N, Kazi SAF, The profile of atopic dermatitis in outpatient department of dermatology Isra University Hospital. Med Forum 2015; 26(7):1013.

10. Kazi N, Rajar UDM, Kazi SAF, Prevalence of skin diseases in patients presenting at the outpatient department of Isra University Hospital Hyderabad: A Clinical Survey. Med Forum 2015; 26(7):47-50. 


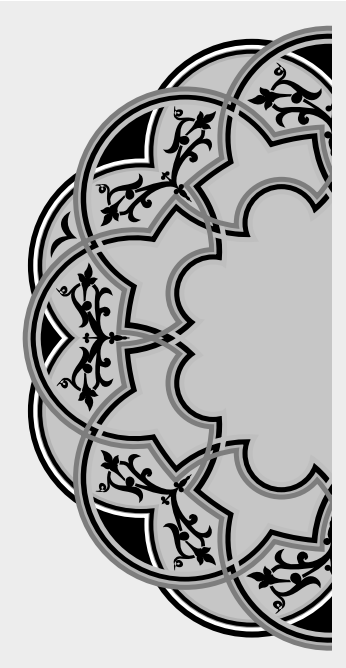

\section{"It's not what you say, It's how you say it."}

\section{Proverb}

\begin{tabular}{|c|l|l|l|}
\hline \multicolumn{3}{|c}{ AUTHORSHIP AND CONTRIBUTION DECLARATION } \\
\hline Sr. \# & \multicolumn{1}{|c|}{ Author-s Full Name } & \multicolumn{1}{|c|}{ Contribution to the paper } & Author=s Signature \\
\hline 1 & Dr. Imran Ahmed Ghirano & Collection of Data \\
\hline 2 & Prof. Dr. Salma Sheikh & Supervision of Study \\
\hline 3 & Dr. Ashique Ali Arain & $\begin{array}{l}\text { Result analysis and article } \\
\text { writing }\end{array}$ \\
\hline
\end{tabular}

